\title{
Reviewing stress in COVID-19 times
}

\begin{abstract}
Covid-19 pandemic, apart from being a serious multi organ virus infectious disease, is a facilitator and also causal etiology of psychological and psychiatric manifestations. Much has been written on depression but manifestations of other behavioral problems appear either together or after its clinical course occurrence, being stress one of the most prevalent of all. Stress raises responses in the body from practically all of the organs such as tachycardia, dyspineia, anxiety and suffering emotions. This is a defense mechanism learnt since primordial times by mammals in occasions of fear of attack. Pathophysiologically it causes a hyper adrenergic state that triggers the symptoms that accompany it. Many metabolic changes occur in parallel and not only the health professional but the population itself must be aware of its potential occurrence and effects so that therapeutic and preventive measures may be installed. The excessive mechanisms of adaptation are responsible for adaptation diseases such as hypertension, infarction, ulcer, etc. The organism is therefore harmed by its own defense mechanisms, a fact that calls for clinical attention and intervention.
\end{abstract}

Keywords: stress, adrenergic status, covid-19, psychological, psychiatric, depression, frustrations

\author{
Volume 4 Issue 5 - 2020
}

\begin{abstract}
Alina MAPN da Silva,' Anita LR Saldanha,' Ana Paula Pantoja Margeotto,' Luiz Carlos Miller Paiva Nogueira da Silva,' André Luis Valera Gasparoto, ${ }^{2}$ Tania Leme da Rocha Martinez'

'Nephrology Department, BP - A Beneficência Portuguesa de São Paulo, São Paulo, Brazil

${ }^{2}$ Intensive Care Unit, BP - A Beneficência Portuguesa de São Paulo, São Paulo, Brazil
\end{abstract}

Correspondence: Tania Leme da Rocha Martinez, BP - A Beneficência Portuguesa de São Paulo, Rua Comandante Ismael Guilherme, 358 - Jardim Lusitânia, CEP 04031 - 120 - São Paulo SP, Brazil, Tel 55 I I 98323-9863, Fax 55 | I 3842-3789, Email tamr@uol.com.br

Received: October 19, 2020 | Published: October 28, 2020

\section{Introduction}

Psychological and psychiatric observations, understandings and interventions on coronavirus infections have gained a major importance role. ${ }^{1-3}$ More recently, especially after SARS-COVID-2 and presently in the pandemics of Covid-19. Depression has led the number of publications related to these conditions but stress also is a matter of great concern. ${ }^{4-7}$ According to Selye ${ }^{8}$ stress is abstract; it does not exist in a pure state and, like life, is very difficult to define. Stress on a rat or a man does not exist as such; it appears to be combined with something, that is, it depends on a specific agent to be produced. We know that stress is causing various somatic diseases, such as gastric or duodenal ulcer, as a result of being the digestive tract "a resonance box of emotions". Through the nerve, hormonal and enzymatic pathways, emotional stress disorganizes digestive functions and causes pathological changes in the gastroduodenal walls. The stress, according to Selye ${ }^{9}$ is nothing more than the tension of the organism, forced to mobilize to face dangerous situations.

Stress can be a specific response to primitive stimuli, such as fear or anger, characterized by the release of epinephrine or norepinephrine, gluco and mineralocorticoids, which produce certain modifications, such as: tachycardia, increased blood flow to muscles, mydriasis, etc., preparing the animal to flee or fight. It is a transitory situation that leaves no sequelae to the body, at most, a temporary syndrome - the general syndrome of adaptation. This is what occurs among animal species and should also be the type of reactional process unique to man if he had not developed certain psychological peculiarities, which he might not have biologically equipped to face. This is the problem of the so-called civilized man: he is not prepared to face more complex stimuli, such as anxieties and frustrations. In view of them, Homo sapiens react differently and certainly inadequately, that is, emotional stress through relative hypercorticalism (increased catecholamine, hypercholesterolemia, hyperglycemia, etc., which produce endothelial injury and atherogenesis).

Selye $^{8}$ called the set of non-specific reactions triggered by chronic stimuli of traumatic, toxic, infectious or emotional origin is called the general syndrome of adaptation; that can be described in detail, the development, always identical, of these biological processes: the organism responds to the various agents that produce stress in an always identical way, that is, through physiological defense mechanisms, which depend largely on the integrity of the adrenal cortex.

The excessive mechanisms of adaptation are responsible for adaptation diseases such as hypertension, infarction, ulcer, etc. The organism is therefore harmed by its own defense mechanisms. The body can therefore be harmed by its own defense mechanisms, a fact that calls for clinical attention and intervention. In the state of stress it is good to investigate the type of emotional and physical tension in which the patient lives so that we can discover the causal or triggering factor of the disease. According to Selye, ${ }^{8}$ Huber, ${ }^{10}$ Masci, ${ }^{11}$ Tennant et al. ${ }^{12}$ the term stress is used by three conditions: as a situation, as an acute reaction and as a long-term reaction.

In stressful situations, all stimuli of the environment can be stressful when they adopt adverse and/or punitive characteristics. These stimuli, to become stressful, also depend on their intensity, frequency and quality (noise, cold, heat, caffeine, nicotine, alcohol, etc., exaggerated). They could be subliminal. In acute stress reactions, the stimulus with adverse and/or punitive characteristics, depending on its quantity and quality can provoke an organic reaction, basically at three distinct levels:

\section{Motor level}

Related to the tension of the striated muscles, verified by electromyography and, subjectively, by the sensations of tension in the face, shoulders, nape, etc.

\section{Vegetative level}

With the release of catecholamines and the excitation of the autonomic nervous system, with sympathetic predominance, and consequent lye, sweating, increased blood glucose, increased respiratory functions, thyroid stimulation and other reactions, which would aim to prepare the body for an attack or flight. 


\section{Subjective-cognoscitive level}

When it affects the subjective experience of a situation with emotional reactions such as shame, anxiety, insecurity or panic and that also affect mental concentration and memory. In the chronic stress reaction, a stress overdose can occur and, in this case, the consequences will depend on individual predisposition (fragile ego); a more sensitive organism with an excitation umbral greater than the more stable ones, and reticular formation is involved in this mechanism. Therefore, it can occur:

An Alarm Stage with an alarm reaction (Acute Stress Reaction) resharpened with each new stressful episode, added to the initial stress.

A Resistance Stage, when the mood is increased to new general excites. The various alarm reactions not reached more easily have their intensity increased and their effects last longer. A Stage of Exhaustion, where stress finally manages to break all organic resistances, with psychic symptoms in which apathy and the feeling of helplessity predominate. The imbalance of reticular formation affects the entire limbic formation, in addition to mood swings. There is a decrease in immune defenses. Palmblad et al. ${ }^{13}$ found in women that stress produced by experimental virus or insomnia produces increased interferon, while phagocytosis and opsoninic activity decrease. Laughter for hours can increase natural killer cells and other kinins such as isolation or anxiety ${ }^{14}$ or cynical hostility ${ }^{15}$ can decrement them. Numerous biochemical tests can aid the development of stress, such as the dosages of epinephrine, norepinephrine, phenylglycol, serotonin, uric acid, cortisol, $17 \mathrm{OH}$ corticosteroids, growth hormone and beta-endorphin, clonidine, lacticidemia, T3, T4, fenflunamine, melatonin, prolactin, etc. ${ }^{16}$

Since Galen's times, emotion has been related to the heart. The attention scans on the physiology of emotion were later located in the brain, mainly in the limbic system; however, there is still much evidence between emotional disorder and vascular system, and there is even an extensive literature on how to intervene and help the patient. ${ }^{17-24}$ In fact of all the circumstances, Covid-19 infected patients should be treated not only for their somatic symptoms but also with interventions regarding their psychological, psychiatric and life quality aspects. ${ }^{25}$

\section{Acknowledgments}

In memoriam Luiz Miller de Paiva.

\section{Conflicts of interest}

No conflict of interest.

\section{References}

1. Rogers JP, Chesney E, Oliver D, et al. Psychiatric and neuropsychiatric presentations associated with severe coronavirus infections: a systematic review and meta-analysis with comparison to the COVID-19 pandemic. Lancet Psychiatry. 2020;7(7):611-627.

2. Levine A, Sacktor N, Becker JT. Studying the neuropsychological sequelae of SARS-CoV-2: lessons learned from 35 years of neuroHIV research. $J$ Neurovirol. 2020;1-15.

3. Szcześniak D, Gładka A, Misiak B, et al. The SARS-CoV-2 and mental health: from biological mechanisms to social consequences. Prog Neuropsychopharmacol Biol Psychiatry. 2021;104:110046.

4. Steenblock C, Todorov V, Kanczkowski W, et al. Severe acute respiratory syndrome coronavirus 2 (SARS-CoV-2) and the neuroendocrine stress axis. Mol Psychiatry. 2020;25(8):1611-1617.
5. Iqbal Y, Al Abdulla MA, Albrahim S, et al. Psychiatric presentation of patients with acute SARS-CoV-2 infection: a retrospective review of 50 consecutive patients seen by a consultation-liaison psychiatry team. BJPsych Open. 2020;6(5):e109.

6. Lee SW, Yang JM, Moon SY, et al. Association between mental illness and COVID-19 susceptibility and clinical outcomes in South Korea: a nationwide cohort study. Lancet Psychiatry. 2020:S2215-0366(20)3042130421.

7. Cameron HA, Schoenfeld TJ. Behavioral and structural adaptations to stress. Front Neuroendocrinol. 2018;49:106-113.

8. Selye H. Annual Report on Stress. v.1. Montreal: Acta Ed.; 1951.

9. Selye H. Stress in health and disease. $1^{\text {st }}$ ed. Sydiney: ButterworthHeinemann; 1976.

10. Huber GKM. Stress y Conflictos: Metodos de Superacion. Madri: Ediciones Paraninfo; 1980.

11. Masci CB. Stress no trabalho: um desafio à medicina moderna / Stress in the work: a challenge to modern medicine Rev bras clin ter. 1988;17(3):89-94.

12. Tennant C, Langeluddecke P, Byrne D. The concept of stress. Aust N Z J Psychiatry. 1985;19(2):113-118.

13. Palmblad J, Cantell K, Strander H, et al. Stressor exposure and immunological response in man: interferon-producing capacity and phagocytosis. J Psychosom Res. 1976;20(3):193-199.

14. La Via MF, Munno I, Lydiard RB, et al. The influence of stress intrusion on immunodepression in generalized anxiety disorder patients and controls. Psychosom Med. 1996;58(2):138-142.

15. Christensen AJ, Edwards DL, Wiebe JS, et al. Effect of verbal selfdisclosure on natural killer cell activity: moderating influence of cynical hostility. Psychosom Med. 1996;58(2):150-155.

16. Miller de Paiva L. Psychosomatic Psychiatry. São Paulo: Garatuja; 1990.

17. Vellingiri B, Jayaramayya K, Iyer M, et al. COVID-19: a promising cure for the global panic. Sci Total Environ. 2020;725:138277.

18. O'Connor DB, Aggleton JP, Chakrabarti B, et al. Research priorities for the COVID-19 pandemic and beyond: a call to action for psychological science. Br J Psychol. 2020;111(4):603-629.

19. Holmes EA, O’Connor RC, Perry VH, et al. Multidisciplinary research priorities for the COVID-19 pandemic: a call for action for mental health science. Lancet Psychiatry. 2020;7(6):547-560.

20. Nieto I, Navas JF, Vázquez C. The quality of research on mental health related to the COVID-19 pandemic: A note of caution after a systematic review. Brain Behav Immun Health. 2020;7:100123.

21. Dunbar F. Psychosomatic Diagnosis. New York: Paul B Hoeber; 1943.

22. Alexander F. Psychosomatic Medicine: Its Principles and Applications. New York: WW Norton; 1950.

23. Groen JJ. Psychosomatic Aspects of Ischaemic (Coronary) Heart Disease. In: Hill OW editor. Modern Trends in Psychosomatic Medicine. London: Butterworths; 1976.

24. Surwit RS, Williams RB, Shapiro D. Behavioral Approaches to Cardiovascular Disease. New York: Academic Press; 1982.

25. Antunes R, Frontini R, Amaro N, et al. Exploring lifestyle habits, physical activity, anxiety and basic psychological needs in a sample of Portuguese adults during COVID-19. Int J Environ Res Public Health. 2020;17(12):4360. 